\title{
Hydration behavior by X-ray diffraction profile fitting of smectite-bearing minerals
}

\author{
Ruarri J. Day-Stirrat ${ }^{1,}{ }^{*}$ and L. Taras Bryndzia ${ }^{1}$ \\ ${ }^{1}$ Shell International Exploration and Production Inc., Shell Technology Center Houston, 3333 Highway 6 South, Houston, Texas, \\ 77082, USA
}

\begin{abstract}
Clay mineral hydration and dehydration processes are reversible at temperatures $<100{ }^{\circ} \mathrm{C}$ and strongly affect wellbore stability, fines migration, permeability, and dispersion of pore pressure. The hydration behavior of smectite-rich material as a function of relative humidity (activity of water, $a_{\mathrm{w}}$, controlled by salinity) and temperature was studied using in situ X-ray diffraction on a material retrieved from coring in the Gulf of Mexico. X-ray diffraction profile fitting was used to explore the competition for water between hydratable phases across a range of relative humidity, $2 \%$ to $90 \%$, and temperature, $25^{\circ} \mathrm{C}$ to $95^{\circ} \mathrm{C}$, conditions. X-ray diffraction profile fitting employed a modified multi-specimen approach in which proportions of minerals were modelled using Ca-exchanged preparations in air-dried and ethylene glycol solvated states. Across the range of hydration states, the mineral proportions and crystallographic parameters remained constant from the multi-specimen approach and only the number of water layers in hydratable phases varied. Quantitative clay mineralogy showed a natural material with a discrete smectite component and a mixed-layered illite-smectite, both capable of hydration/dehydration. Results of this study showed the discrete smectite component and the mixed-layered illite-smectite hydrated at different rates with discrete smectite up-taking more water at lower relative humidity than the mixed-layered illitesmectite. Over geological time this study highlights the non-static nature of smectite hydration with implications of long-term creep and permeability behavior.
\end{abstract}

\section{Introduction}

Smectite, and its mixed layer mineral equivalent illitesmectite, is one of the most ubiquitous clays minerals in terrestrial and marine environments. Smectites can react quickly to changes in hydration, with associated textural changes, most obviously observed as cracks in soils or buildings with foundations built on smectite-rich soil. Studies on the hydration behavior of reference clays and shales sought to explore the swelling and stability behavior of clays and shales for wellbore stability and drilling fluid design (1-3). These workers found that the ability of various salts $\left(\mathrm{NaCl}, \mathrm{CaCl}_{2}, \mathrm{KCl}\right)$ to inhibit the hydration of reference clays (sodium montmorillonite, calcium montmorillonite, illite) was related to the counterbalancing (interlayer) cation of the clay species. Benchtop adsorption isotherms on reference clays $(4,5)$ and swelling tests to simulated borehole conditions (6) have probed the macroscopic behavior of shales or mudrocks to changes in hydration state, either as a function of relative humidity or changes in water activity (salinity). Smectites have the remarkable ability to expand and contract their crystal structure in response to the availability of water (strictly hydrated cations) without losing their crystallographic integrity. In X-ray diffraction this manifests as the migration of the basal peak of expandable clays (smectites) in response to hydration state (or relative humidity), and temperature, and as a function of interlayer cation type.
Water in the interlayer space of an expandable clay is a layer (or many). Its exact thickness relates to the cation association, along with the localization and size of charge originating in the clay structure, although much complexity exists $(7,8)$. The thickness of these water layers is described as an integral, either $0,1,2$ or 3 , (notation $0 \mathrm{~W}, 1 \mathrm{~W}, 2 \mathrm{~W}, 3 \mathrm{~W}$ ) layers of water (e.g. 8) that increase with increases in relative humidity, or a decrease in salinity. Relative humidity $(\mathrm{RH})$ or water activity $\left(\mathrm{a}_{\mathrm{w}}\right)$ is a function of brine salinity. Distilled water has an $\mathrm{a}_{\mathrm{w}}$ of 1.0 , whereas an $\mathrm{NaCl}$ saturated brine solution has an $a_{w} \sim 0.75$. Equation (1) is the definition of $\mathrm{a}_{\mathrm{w}}$ :

$$
\mathrm{a}_{\mathrm{w}}=\mathrm{p} / \mathrm{p}_{0}
$$

where $\mathrm{p}$ is the vapor pressure of water in the solution and $\mathrm{p}_{0}$ is the vapor pressure of pure water at the same temperature. The relationship of $\mathrm{a}_{\mathrm{w}}$ to $\mathrm{RH}$ may be expressed as the relative humidity of air in equilibrium with a sample and is called the Equilibrium Relative Humidity (ERH):

$$
\mathrm{ERH}=\mathrm{a}_{\mathrm{w}} * 100 \%
$$

At surface conditions, $15-25{ }^{\circ} \mathrm{C}$ and $40-60 \%$ relative humidity, previous work $(4,5,9)$ shows this to be the zone between coexisting $1 \mathrm{~W}$ and $2 \mathrm{~W}$ hydration states (10). X-ray diffraction studies control this expansion effect with polar organic molecules (ethylene glycol or less commonly glycerol) allowing the clay structure to expand to a consistent extent.

\footnotetext{
* Corresponding author: Ruarri.Day-Stirrat@Shell.com
} 
This paper addresses the hydration/dehydration behavior of naturally occurring smectite-rich material representative of the mineralogy in the shallow section of the Gulf of Mexico (GOM) dominated by recent PlioPleistocene sedimentation. We performed controlled RH and temperature experiments, to illuminate the hydration behavior of this natural material and then merge the multi-specimen approach for clay mineral characterization $(11,12)$ with a hybrid approach to profile fitting of $\mathrm{RH}$ experimental data similar to that employed by Ferrage (7). Finally, we seek to link this back to the macroscopic adsorption of water on natural materials and illuminate, at the Angstrom scale, where and how water moves from being structural water to being more like pore water. This has significant implications for assumed grain densities in petrophysical characterization of sedimentary rocks and modeling of overpressures at elevated temperatures or increased salinities in the absence of smectite illitization (13). Further, the expandability and, hence, the charge character of smectite materials dictates the volume of fluids associated with a clay aggregate and defines the starting position for any consolidation profile (void ratiovertical effective stress relationship). The double layer around the smectite particle is affected by surface charge (area) and salinity of the associated brine. Smectite has a strong affinity for this fluid and, while not in particle contact in suspension, the particle center-to-center distance is defined by the smectite's reaction to its encapsulating fluid. Therefore, consolidation is driven by how fast this fluid can be moved or manipulated by salinity.

\section{Samples, Sample Preparation and Experimental design}

Eugene Island mudrocks were acquired from conventional core taken from two wells in the Eugene Island 330 Field in the Gulf of Mexico. The wells cored a Pliocene-Pleistocene salt-withdrawal mini basin filled with diagenetically immature sediments sourced from the continental US. Original pore pressure, core, and geomechanics based studies tested much of this material's in situ behavior. After the cores lost their original water contents, they were ground and homogenized to produce a standard material for laboratory testing using resedimentation techniques (1416).

A series of extraction steps to isolate clay minerals were performed to aid in the preferred orientation of clay minerals for X-ray analysis. The basis of the method is the so-called "Jackson Treatment" (17) and consists of several mechanical and chemical steps to produce an oriented $<2 \mu \mathrm{m}$ fraction filter peeled onto a glass slide.

Diffraction patterns for quantitative analysis were collected on a Philips PW1700. The radiation source was $\mathrm{CuK} \alpha$ with a wavelength of $0.154 \mathrm{~nm}$, using steps of $0.05^{\circ} 2 \theta$ over the $2 \theta$ range of 2 to $47^{\circ}$. The counting time at each step was $2 \mathrm{~s}$. Patterns were collected in two states, first air-dried (AD) and then on the sample that has been treated with ethylene glycol (EG) vapor for 60 minutes. Patterns were modelled using the NEWMOD2 ${ }^{\circledR}$ program (18).

To systematically test the hydration and temperature effects on swelling clays, a humidity chamber attached to a different X-ray Diffraction device was used. A PANalytical Empyren X-ray diffractometer with an externally controlled humidity chamber allowed for a series of RH experiments to be run. The humidity chamber uses a humidified gas stream generated with a humidity controller. The gas passes through heated pipes into the chamber, comes out of two rows of holes perpendicular to the $\mathrm{X}$-ray beam and generates a humid atmosphere encasing the heated sample. A fan removes the excess humidity to avoid condensation. The chamber is also equipped with a "TCU 110 " temperature control unit with a Pt 100 sensor, designed to control the temperature directly at the sample (Anton Paar $\mathrm{GmbH}$ ).

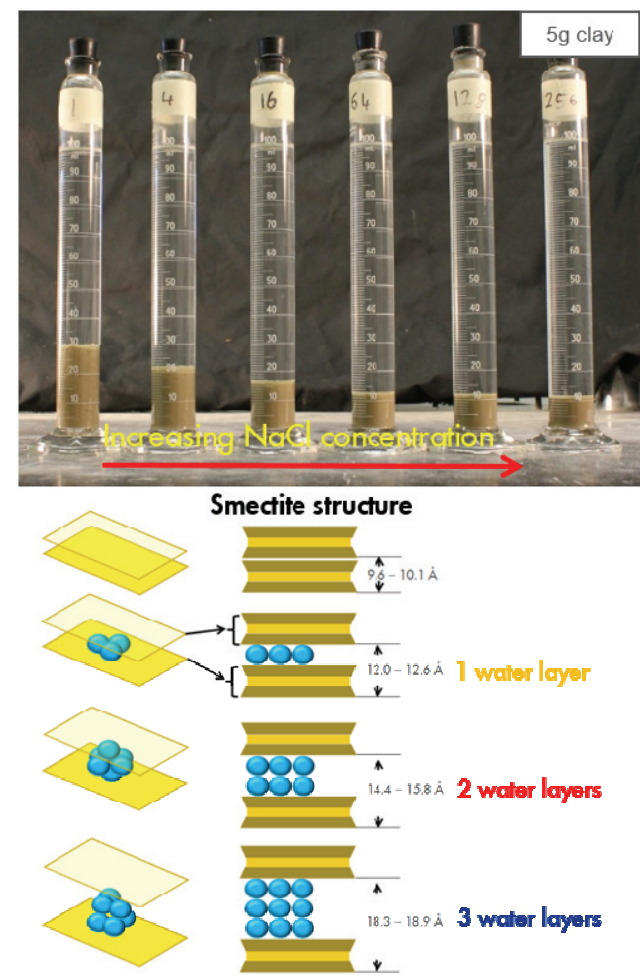

Fig. 1. 5 grams of Eugene Island sourced mudrock shows variable degrees of expansions in brines of variable $\mathrm{NaCl}$ content. Swelling of expandable clays is controlled by the water activity $\left(a_{w}\right)$ which is a function of relative humidity. Sea water has a salinity of $35,000 \mathrm{ppm}(3.5 \mathrm{wt} . \%$ and $35 \mathrm{~g} / \mathrm{L})$. Brine salinities ranges from $1,4,16,64,128$, and $256 \mathrm{~g} / \mathrm{L}$ $\mathrm{NaCl}$. These salinities also control the double layer thickness. Tetrahedral-octahedral-tetrahedral layers of smectite (2:1 layers) are depicted as sheets with progressively more hydrated cations between repeating sheets. Water-layer hydration in smectite material showing progressively greater expansion with increasing water contents and associated basal expansions in Ångstroms ranges with cation type.

Experiments were performed over a range of $\mathrm{RH}$ conditions, from $2 \%$ to $90 \%(+/-0.5 \%)$ on the same prepared material as was used for initial quantification. The experimental sequence began at $25^{\circ} \mathrm{C}$ and from $2 \%$ $\mathrm{RH}$ (effective zero) up to $90 \% \mathrm{RH}$ in $10 \%$ increments. 
Temperature progressively increased in $10^{\circ} \mathrm{C}$ increments to $95^{\circ} \mathrm{C}$ using the same relative humidity steps (some combinations of elevated temperature and relative humidity cannot be achieved). The timing on the heating and relative humidity changes are considered instantaneous from a geological perspective and take around 6 minutes in real-time. Previous work by Schleicher et al. (19) showed that up to $125^{\circ} \mathrm{C}$ of instantaneous or prolonged heating (5 hours) smectite recovered almost $100 \%$ of its hydration state at ambient conditions, but at higher temperatures less recovery was observed. Therefore, these experiments were designed to a maximum of $95^{\circ} \mathrm{C}$ and post-hydration re-analysis of the same materials was performed to assess whether temperature induced mineral change had occurred.

\section{Modeling}

The approach to modeling a diffraction pattern is to, first, apply the multi-specimen method, in which the Caexchanged and ethlyene glycol (EG) solvated experimental pattern is simulated. The second step is to use the crystallographic parameters defined in the Caexchanged and ethlyene glycol solvated state and change to an air-dried (AD) state. The multi-specimen method is satisfied when EG and $A D$ yield the same modal proportions of phases. The NEWMOD2 ${ }^{\circledR}$ software package used was extended to model the diffraction behavior for a series of hydration states for the $25^{\circ} \mathrm{C}$ sample of the Eugene Island sourced material. However, it is important to note that smectite may exist in more than two hydration states within an individual crystallite, NEWMOD2 ${ }^{\circledR}$ cannot model more than two hydration states for the same mineral. The modeling is, therefore, multicomponent. Three phases, illite, kaolinite, chlorite, were fixed using the same parameters and proportions that were modeled using the standard multi-specimen approach. They contribute to the overall pattern character but not to the hydration behavior. Illitesmectite (I-S) has one variable that can change, namely the number of water layers in the smectite. Smectite was treated as a discrete phase with $0 \mathrm{~W}, 1 \mathrm{~W}, 2 \mathrm{~W}$, or $3 \mathrm{~W}$ layers, or a continuous interstratification of water-layer types in a random (R0) configuration. Since the coherent stacking domain was small $(\mathrm{N}=3)$ no ordering of water layers was modeled. The basal spacings of smectite (Fig. 1) are as follows: dehydrated [0W, $\mathrm{d}_{001}$ 9.7-10.2 $\AA$ ], mono-hydrated [1W, d(001) 11.6-12.9 $\AA]$, bi-hydrated $[2 \mathrm{~W}, \mathrm{~d}(001)$ 14.9-15.8 $\AA]$, and tri-hydrated $[3 \mathrm{~W}+$, $\mathrm{d}(001) 18-20 \AA]$ layers. The latter spacing is large and may be more reflective of $4 \mathrm{~W}$. Generally, a $2 \mathrm{~W}: 0 \mathrm{~W}$ interstratification was avoided under the assumption that $0 \mathrm{~W}: 1 \mathrm{~W}$ or $1 \mathrm{~W}: 2 \mathrm{~W}$ is more likely to occur.

\begin{tabular}{|c|c|c|c|c|c|c|}
\hline & Mineral & 幂 & 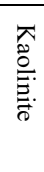 & 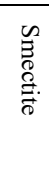 & $\underset{\stackrel{\rho}{\varrho}}{\stackrel{\rho}{\ominus}}$ & 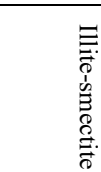 \\
\hline & & & & & & I-S (R0) \\
\hline & Reichweite & & & & & 0 \\
\hline & Proportions & & & & & $76: 24$ \\
\hline & $\mathrm{N}(*)$ & 14 & 23 & 3.5 & 9 & 8 \\
\hline & $\begin{array}{l}\text { Fe-Content } \\
(* *)\end{array}$ & 0 & & & 1.5 & \\
\hline Fraction & $<2 \mu \mathrm{m}$ & & & & & \\
\hline $\begin{array}{l}\text { Eugene } \\
\text { Island }\end{array}$ & & 15 & $7 \%$ & 43 & $5 \%$ & 30 \\
\hline $\begin{array}{l}\text { Eugene } \\
\text { Island } \\
\text { (post- } \\
\text { test) }\end{array}$ & & 16 & $4 \%$ & 42 & 2 & 36 \\
\hline
\end{tabular}

Table 1. Relative wt. $\%$ of clay minerals in the $<2 \mu \mathrm{m}$ fraction of Eugene Island material. $\mathrm{N}^{*}$ is the coherent stacking domain.

\section{Results}

Quantification of the clay minerals in the $<2 \mu \mathrm{m}$ fraction using NEWMOD2 ${ }^{\circledR}$ (Table 1) reveal this sample to be dominated by discrete smectite and a non-ordered (R0) illite-smectite (I-S) with illite and smectite in the proportions 76:24. Additionally, there is discrete illite, kaolinite, and chlorite present. Post-hydration and heating to $95^{\circ} \mathrm{C}$ show little signs of smectite peak degradation, hence the similarity between pre- and postexperiment relative proportions.

Eugene Island sourced material has a complex response as relative humidity changes from $2 \%$ to $90 \%$ at low temperatures $\left(25^{\circ} \mathrm{C}\right)($ Fig 2). The smectite peak collapsed to $0 \mathrm{~W}\left(8.8^{\circ} 2 \theta\right)$ at $2 \%$ relative humidity, which is the same position as the illite peak, but expands to greater basal $d(001)$ spacings at higher levels of relative humidity. The basal $d(001)$ reflection $\left(8.8^{\circ} 2 \theta \mathrm{CuK} \alpha\right)$ is more intense at low humidity.

The hydration behavior of Eugene Island smectite-rich materials suggests that between low and moderate hydration of smectite, it should be treated as a solid solution of hydrous and anhydrous phases that are randomly interstratified with any combination of $2 \mathrm{~W}$ or $1 \mathrm{~W}$ or $0 \mathrm{~W}$. Between 0 and $40 \%$ relative humidity the $0 \mathrm{~W}$ component of smectite decreases and the $1 \mathrm{~W}$ increases. Above 40\% relative humidity (Figs 2, 3, and 4) a $2 \mathrm{~W}$ component appears. Above $70 \%$ relative humidity there is a significant change, the I-S(R0)76:24 phase has converted to a $2 \mathrm{~W}$ phase, and the smectite sees a jump to large d(001) spacings (Fig. 4). No 0W remains in the diffraction pattern. Concomitantly, the $1 \mathrm{~W}$ and $2 \mathrm{~W}$ slightly decline in abundance and the smectite phases tend to be pure water layer forms ( $1 \mathrm{~W}$ or $2 \mathrm{~W})$. At $40 \% \mathrm{RH}$ and $25{ }^{\circ} \mathrm{C}$ (Fig 2), a complex X-ray diffraction pattern is present demonstrated by the flatline between $\sim 6.0$ and $8.8^{\circ} 2 \theta$. In fact, this broad area is comprised of three I-S phases in varying hydration states and two smectite phases (Fig. 3). 


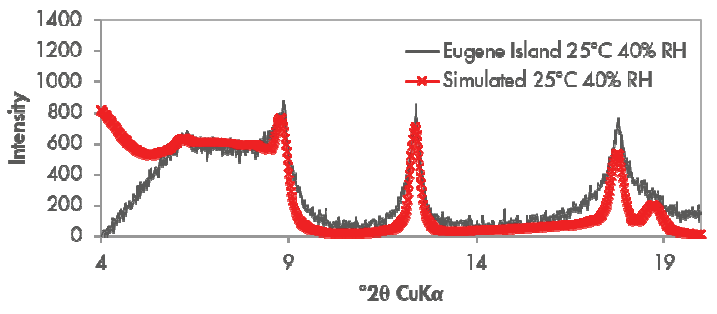

Fig. 3. Measured and simulated diffraction patterns for the $40 \%$ relative humidity experiment at $25^{\circ} \mathrm{C}$.

Viewing the diffraction pattern as a stepped process of $0 \mathrm{~W}, 1 \mathrm{~W}, 2 \mathrm{~W}$ or $3 \mathrm{~W}$ water layers does not capture how smectite hydrates. At any relative humidity, smectite consists of multiple hydrated states that progressively, but non-uniformly, shift to greater water contents and simply describing them as one hydration phase does not capture the complexity of the observed hydration behavior. There is a discontinuity in hydration behavior between 70 and $80 \%$ relative humidity as the smectite jumps to a $3 \mathrm{~W}$ layer complex.

\section{Discussion}

Krushin (20) recently proposed a method for modeling pore fluid pressure in clay rich mudrocks, utilizing a model in which the water content (WC) of smectite was normalized to its cation exchange capacity (CEC). The WC was based on benchtop adsorption isotherms from experiments covering a range of $\mathrm{RH}$ conditions. Data from $(2,4,5)$ were normalized for porosity (water content, WC) and CEC (CEC being a proxy for surface area). Those studies show a general collapse (Fig. 5) of CEC normalized water vapor sorption isotherms as a function of relative humidity. The wellbore stability data from (2), and sodium and calcium saturated smectite adsorption data from Likos and Lu (4) show separations in water vapor sorption between materials with different surface area properties (Fig 5). The studies $(4,5)$ by Likos and Lu pointed strongly to the effect of cation valence in dictating the shape of the curves in Figures $5 \mathrm{~A}$ and $5 \mathrm{~B}$. When this concept and literature data are augmented with previously unpublished Shell legacy data on wellbore stability, based on benchtop swelling tests, the trends are observed to generally hold true.

For Eugene Island material, the water contents were calculated from the profile fitting of smectite phase hydration across relative humidity at $25^{\circ} \mathrm{C}$ (Figs. 4 and 5). CEC for Eugene Island sourced material is taken from mineralogy and set to $50 \mathrm{mEq} / 100 \mathrm{~g}$. The following assumptions were made: in $1 \mathrm{~W}, 2 \mathrm{~W}$, and $3 \mathrm{~W}$ water layer states water is coordinated as 4,6 , and 8 molecules (molar mass $18 \mathrm{~g} / \mathrm{mol}$ ), respectively, and that the molar mass of smectite and illite-smectite is $757 \mathrm{~g} / \mathrm{mol}$. Yielding water contents for $1 \mathrm{~W}, 2 \mathrm{~W}$, and $3 \mathrm{~W}$ states as $9.5 \%, 14 \%$, and $19 \%$ (molar mass), respectively. In water vapor sorption space (Fig 5), the Eugene Island sourced material at $<70 \%$ relative humidity overlays the water content data from (3). Above $80 \%$ relative humidity the jump to $3 \mathrm{~W}$ fitted from $\mathrm{X}$-ray diffraction data overlay the trend defined by $\mathrm{Ca}$-smectite adsorption experiments of (4).

This relationship suggests that in CEC normalized data, points above $0.5 \mathrm{WC} / \mathrm{CEC}$ the mudrock is effectively not in grain contact and water is best described as pore water. X-ray diffraction patterns for Eugene Island materials at $90 \%$ relative humidity has a $\mathrm{d}(001)$ that is approaching a point where units of the coherent stacking domain are so far apart and misaligned that the Bragg equation is not satisfied and no diffraction occurs. This has significant implications for resedimentation (reconstituted) consolidation studies.

Bulk water contents of shales decrease with increasing temperature and vertical effective stress. In the absence of diagenesis, CEC does not change and at any given temperature, the $\mathrm{WC} / \mathrm{CEC}$ versus relative humidity curve may be used as a pseudo-consolidation curve (20) in which water loss can be explained by a progressive loss of water layers from $3 \mathrm{~W}$ to $2 \mathrm{~W}$ and finally to $1 \mathrm{~W}$. A $0 \mathrm{~W}$ layer smectite is extremely unlikely in most basins as clay mineral diagenesis probably occurs before the necessary temperature or relative humidity conditions are met.

The XRD study presented here shows the relative ease with which the $3 \mathrm{~W}$ layer is reduced to a $2 \mathrm{~W}$ layer type. The $2 \mathrm{~W}$ layer smectite persists to quite low values of relative humidity or elevated temperatures. The modeling of XRD patterns shows that the hydration state of smectite does not change abruptly after the $3 \mathrm{~W}$ layer is lost and that multiple hydration states may exist in the same sample over a range of relative humidity. The above argument suggests that fluid pressures may be generated by dehydration of smectite in a compacting shale section as water is moved from interlayer positions to pore fluid by changes in $a_{w}$ alone. The generated pore fluid pressure can only dissipate if the shale in question has a sufficiently large permeability conducive to fluid flow and dissipation of pore fluid pressure (13).

Alternatively, Fig. 5 also describes the starting position of a consolidating material in a Constant-Rate of Strain test where WC/CEC is controlled by grain size, clay mineral type, brine salinity, and cation affinity. Concomitantly, a mudstone with a high-water content will have a high Liquid Limit. Initial void ratio of a soil is, therefore, controlled by the expandable nature of its mineral constituents and their variable affinity to sequester hydratable cations (Fig. 6) and by association the size of the electric double layer around a clay particle. Void ratio - vertical effective stress curves (consolidation) for smectite-rich soils show significant changes in void ratio over small increments of loading (VES). The boundary between pore water, bound water, and interlayer water, therefore, becomes decidedly blurred. 

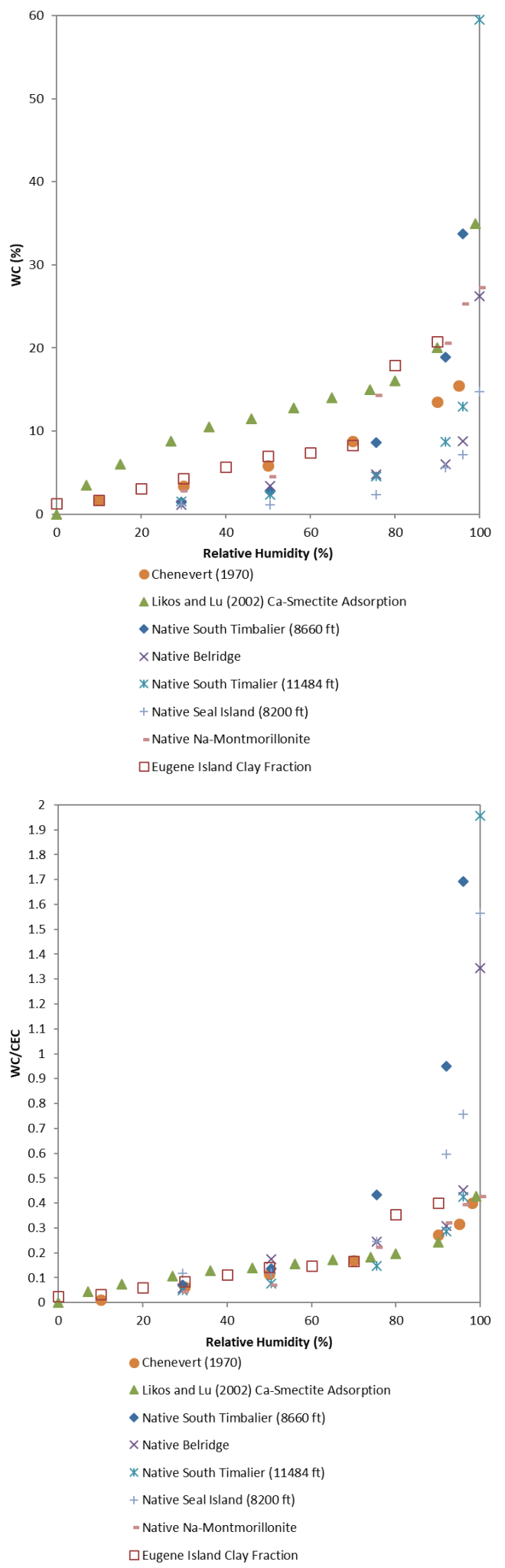

Fig. 5 A) CEC normalized water vapor sorption for swelling tests from (3) and previous unpublished Shell Gulf of Mexico mudrocks and a calcium-smectite (4). The Eugene Island clay fraction data is a calculated water content (WC) from NEWMOD $2^{\circledR}$ profile modeling. B) Water contents differ below $70 \%$ relative humidity in response to differences in CEC and interlayer cation
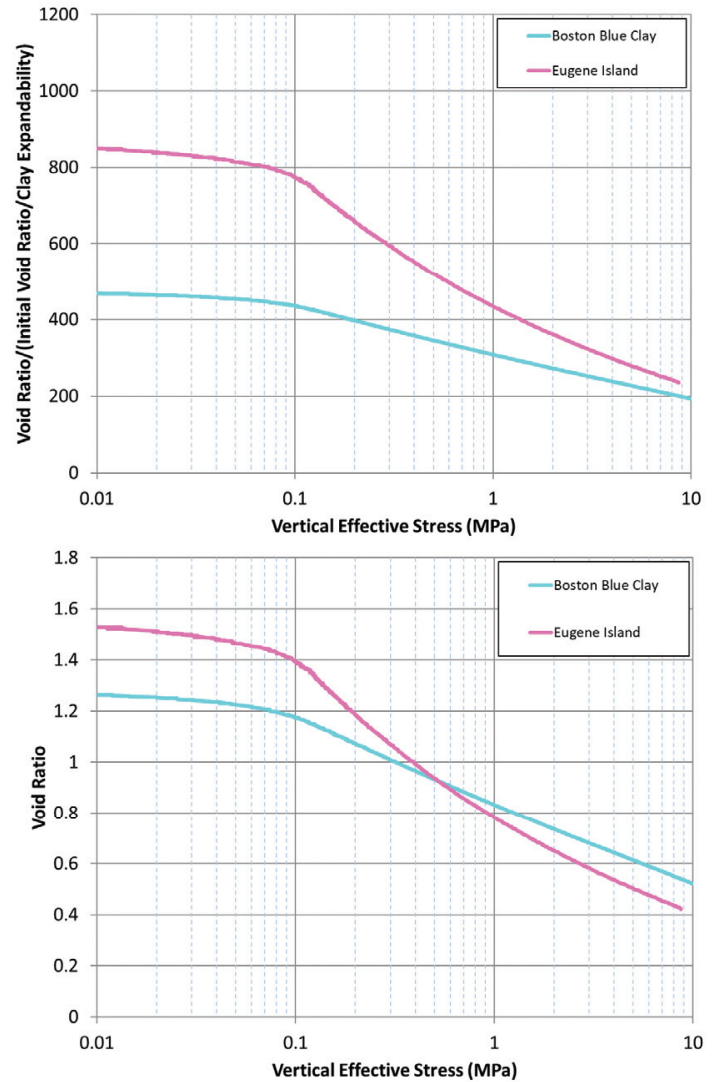

Fig. 6 Consolidation profiles for Eugene Island and Boston Blue Clay (21) performed using a brine salinity of $16 \mathrm{~g} / \mathrm{L} \mathrm{NaCl}$. The Boston Blue Clay is an illite and mica rich mudrock with a very low proportion of expandable clays. When void ratio is normalized for initial testing conditions and clay expansion potential (from XRD data) significant separation occurs and relates to the surface area and electric double layer differences between clay mineral components. Initial void ratio will be sensitive to salinity and clay type.

\section{Conclusions}

This paper makes the case that all basic characterization tests should be performed, and X-ray profile modelling acquired to fully characterize the smectite proportions in geotechnical samples. Clay fraction and Atterberg Limit tests go a long way to describing and characterizing the class of material but as this paper shows, considerable variability exists within the $<2 \mu \mathrm{m}$ fraction and sensitivity of geotechnical properties of clay rich materials to salinity, cation type (valence) should be considered. Clay mineral hydration (and dehydration) are reversible processes at temperature $<95^{\circ} \mathrm{C}$, and they strongly affect wellbore stability due to swelling, fines migration due to particle size relative to pore throat size, permeability due to pore and pore throat occlusion, and pore pressure dispersion by changes in the basal spacing of the mixed layer I-S and the gain and loss of water. Some clay minerals can exchange cations in their structure, which complicates hydration and dehydration behavior. This paper models the hydration behavior of smectite-rich mudstones, allowing for a stronger 
prediction of their behavior in the subsurface. Modeling of the hydration experiments showed that smectite and illite-smectite exist as complex mixtures with variable hydration states across relative humidity ranges of 2$90 \%$ and, by analogy, temperatures $<95^{\circ} \mathrm{C}$. Compaction is assumed to be essentially irreversible since one cannot uncompact a rock mass to its original "preconsolidation" state, but changes in $\mathrm{a}_{\mathrm{w}}$ can impact the molar volume of solids in the matrix by moving water into and out of the expandable clay structures.

\section{References}

1. Chilingarian, G.V. and Knight, L. Relationship between pressure and moisture content of kaolinite, illite and montmorillonite clays. AAPG Bulletin, 44(1): 101-106. (1960)

2. Chenevert, M.E. Shale alteration by water adsorption. Jornal of Petroleum Technology: 1141-1147 (1970)

3. O'Brien, D.E. and Chenevert, M.E. Stabilizing sensitive shales with inhibited potassium-based drilling fluids. Jornal of Petroleum Technology: September p. 1089 (1973)

4. Likos, W.J. and $\mathrm{Lu}, \mathrm{N}$. Water vapor sorption behavior of smectite-kaolinite mixtures. Clays and Clay Minerals, 50(5): 553-561 (2002)

5. Likos, W.J. and Lu, N. Pore-scale analysis of bulk volume change from crystalline interlayer swelling in $\mathrm{Na}$ - and $\mathrm{Ca}$-Smectite. Clays and Clay Minerals, 54(4): 515-528 (2006)

6. Ewy, R.T. and Stankovic, R.J. Shale swelling, osmosis, and acoustic changes measured under simulated downhole conditions. SPE Drilling and Completions, 25(2): 177-186 (2010)

7. Ferrage, E., Lanson, B., Michot, L.J. and Robert, J.-L. Hydration Properties and Interlayer Organization of Water and Ions in Synthetic Na-Smectite with Tetrahedral Layer Charge. Part 1. Results from X-ray Diffraction Profile Modeling. Journal of Physical Chemistry, 114: 4515-4526 (2010)

8. Ferrage, E. Investigation of the interlayer organization of water and ions in smectite from the combined use of diffraction experiments and molecular simulations. A review of methodology, applications, and perspectives. Clays and Clay Minerals, 64(4): 348-373 (2016)

9. Moore, D.M. and Hower, J. Ordered interstratification of dehydrated and hydrated Na-Smectite. Clays and Clay Minerals, 34: 379384 (1986)

10. Sato, T., Wantanabe, T. and Otsuka, R. Effects of layer charge, charge location, and energy change on expansion properties of dioctahedral smectites. Clays and Clay Minerals, 40: 103113 (1992)

11. Drits, V.A. and Sakharov, B.A. X-ray structure analysis of interstratified minerals, Nauka, Moscow, 225 p., 1976 (in Russian) (1976)
12. Sakharov, B.A., Lindgreen, H., Salyn, H. and Drits, V.A. Determination of illite-smectite structures using multispecimen X-ray profile fitting. Clays and Clay Minerals, 47: 555-566 (1999)

13. Day-Stirrat, R. J., Bryndzia, L.T., Schleicher, A. M., Adriaens, R., Hofmann, R., and Fleming, P.B. Hydration behavior by X-ray diffraction profile fitting of smectite-bearing minerals in a Plio-Pleistocene mudrock from Eugene Island, Gulf of Mexico. Marine and Petroleum Geology v102, p.86-100 (2019)

14. Casey, B., Germaine, J.T., Flemings, P.B., Reece, J.S., Gao, B. and Betts, W. Liquid limit as a predictor of mudrock permeability. Marine and Petroleum Geology, 44: 256-263 (2013)

15. Adams, A. Permeability anisotropy and resistivity anisotropy of mechanically compressed mudrocks, Massachusetts Institute of Technology, 322 pp (2014)

16. Fahy, B. The influence of salinity on the mechanical behavior of high plasticity soils, Massachusetts Institute of Technology, $238 \mathrm{pp}$ (2014)

17. Jackson, M.L. Soil Chemistry Analysis Advanced Course. Published by Author (1974)

18. Moore, D.M. and Reynolds, R.C.J. X-ray diffraction and the identification and analysis of clay minerals. Oxford University Press, Oxford, New York (1997)

19. Schleicher, A.M., Boles, A. and Van der Pluijm, B. Response of natural smectite to seismogenic heating and potential implications for the 2011 Tohoku earthquake in the Japan Trench. Geology, 43(9): 755-758 (2011)

20. Krushin, J.T. Quantifying shale pore pressure by modeling the controls on compaction and porosity. Interpretation, 2(1): SB79-SB88 (2014)

21. Casey, B. The Consolidation and Strength Behavior of Mechanically Compressed FineGrained Sediments. MIT PhD Thesis Cambridge, MA, USA (2014) 